\title{
Análise epistemológica das concepções de relação entre ciência e religião de pós- graduandos do Instituto de Biofísica da UFRJ
}

\author{
Epistemological analysis of the conceptions of \\ relationship between science and religion of postgraduate \\ students of the Institute of Biophysics of UFRJ
}

\author{
Vinícius Carvalho da Silva \\ Pós-doutorando em Saúde \\ Pública pelo Instituto de \\ Medicina Social da UERJ \\ Doutor em Filosofia \\ da Ciência e Teoria do \\ Conhecimento pela \\ Universidade do Estado \\ do Rio de Janeiro \\ Professor substituto \\ na Universidade Federal \\ do Tocantins \\ viniciusfilo@gmail.com \\ Orcid: https://orcid. \\ org/0000-0002-1061-2727
}

Recebido em: 10/10/2018 Aceito em: 19/12/2018
Resumo

Neste trabalho analisamos quatro tipos de relação entre ciência e fé religiosa, adotando como parâmetro os modelos elaborados pelo biólogo molecular Dennis Alexander. Conforme tais modelos, os tipos mais comuns de relacionamento entre os dois sistemas de crenças e práticas são conflito, não-interferência, fusão e complementaridade. Em 2017 aplicamos questionários com questões sobre natureza da ciência e relação entre ciência e fé para pesquisadores, estudantes de pós-graduação do Instituto de Biofísica Carlos Chagas Filho, da Universidade Federal do Rio de Janeiro, com o intuito de verificar como concebem a relação entre ciência e fé com base nos modelos teóricos aqui adotados. A segunda parte deste trabalho consiste em uma análise estatística e conceitual dos resultados obtidos.

Palavras-chave: Ciência, Fé, Natureza da ciência, Crenças, Religião.

\section{Abstract}

In this work we analyze four types of relationship between science and religious faith, adopting as a parameter the models elaborated by the molecular biologist Dennis Alexander. According to such models, the most common types of relationship between the two systems of beliefs and practices are conflict, non-interference, fusion, and complementarity. In 2017, we conducted a survey with questions about the nature of science and the relationship between science and faith for researchers, postgraduate students of the Carlos Chagas Filho Institute of Biophysics, of the Federal University of Rio de Janeiro, in order to verify their conceptions of relationship between science and faith based on the theoretical models adopted here. The second part of this work consists of a statistical and conceptual analysis of the results obtained.

Key words: Science, faith, nature of science, beliefs, religion 


\section{Introdução}

As relações, tensões e interações entre ciência e religião constituem um importante objeto para os estudos de ciências em sentido amplo, isto é, para a filosofia, a história, a sociologia da ciência e demais áreas afins. Pensamos que tais interações históricas são complexas, isto é, são relações epistemológicas, culturais, sociais, políticas e institucionais. Há séculos que pensadores se debruçam sobre a questão da relação entre ciência e fé. Desde Galileu, Newton, e Descartes, até Planck, Einstein e outros. Para Max Planck em Ciência e Religião, ambas animam-se mutuamente e compartilham do pressuposto metafísico comum de que o real é ordenado e unificado em leis (PLANCK, 2012, p. 234). Einstein também sustentou que o que anima a pesquisa científica é uma espécie de religiosidade e se interessou pela evolução histórica da religião e sua relação com a ciência (EINSTEIN, 1981, p.13). A conferência ministrada por Planck em 1937 sobre ciência e religião completou 80 anos em 2017, ano em que realizamos a pesquisa que motivou este trabalho no Instituto de Biofísica da UFRJ para verificar como mestrandos e doutorandos do Instituto concebiam as relações entre ciência e religião.

Os estudos das interações entre ciência e religião foram institucionalizados com a criação de centros de pesquisa dedicados ao tema, como é o caso do The Ian Ramsey Centre for Science and Religion da Universidade de Oxford, fundado em 1985, e do The Faraday Institute for Science and Religion, ligado a Universidade de Cambridge, inaugurado em 2006, do qual o biólogo Dennis Alexander, cuja obra utilizamos nesse artigo, é Diretor Emérito. Uma obra de referência neste campo é o companion publicado pela Universidade de Cambridge e organizado pelo professor Peter Harrison, diretor do Ian Center de Oxford (2010). Esta linha de pesquisa constitui um campo consolidado. É neste que o presente trabalho está inserido. Tal campo envolve o trabalho conjunto de muitas disciplinas, tais como filosofia, teologia, sociologia, história, antropologia e as mais diversas ciências naturais, como física, química e biologia. São abordadas questões, por exemplo, como a origem do universo e as interações, tensões e diálogos entre a cosmologia e a teologia da criação, ou a origem da vida, e as relações entre as explicações religiosas e as teorias científicas. Neste trabalho nosso interesse não é o de verificar como as duas tradições dialogam acerca de um problema comum, mas o de analisar como um grupo de mestrandos e doutorandos do Instituto de Biofísica da UFRJ compreende a relação entre ciência e religião.

\section{Modelos de interação entre ciência e religião}

O físico e teólogo Eduardo R. Cruz, em Cientistas como Teólogos e Teólogos como Cientistas, lembra que Ian Babour concebeu quatro possibilidades de relacionamento entre religião e ciência: (1) conflito, (2) independência, (3) diálogo e (4) integração. O "conflito" povoaria o imaginário popular e a comunicação não especializada, ao menos nos Estados Unidos e em países da Europa que registram um decrescimento da fé religiosa. Será que o mesmo se passa entre brasileiros? A “independência” seria a posição da maior parte dos cientistas e, dentre as religiões, da Igreja Católica de Roma. O "diálogo" é muito presente entre cientistas e teólogos, que concebem que as duas atividades podem oferecer algo, uma à outra, enriquecendo-se mutuamente. A "integração" é muito comum em novos movimentos religiosos e misticismos. Seus entusiastas, por exemplo, podem crer que a mecânica quântica, é uma nova forma de espiritualidade, comprovando a existência de Deus e de fenômenos espirituais ${ }^{1}$. O biólogo molecular Dennis Alexander propôs outros modelos para

1 Conforme Polkinghorne é preciso precaução com a "moda quântica" (POLKINGHORNE, 2012, p. 109). Oswaldo Pessoa Jr. em O fenômeno cultural do misticismo quântico ressalta que o chamado "misticismo quântico", é considerado infundado, e mesmo ignorado e ridicularizado pela maioria dos cientistas naturais (PESSOA JR, 2011, p. 296). Todavia, algumas interpretações teístas sérias da MQ também foram propostas. Em stricto sensu, a mecânica quântica é um conjunto de equações, cálculos e princípios, ou seja, um sistema lógico de proposições acerca da natureza da matéria em escalas subatômicas. A rigor, não existe "a" mecânica quântica, mas diversas abordagens, modelos, teorias quânticas. "O que elas nos dizem?", "O que elas comprovam?". Cremos que sejam as perguntas erradas. Mais adequado seria perguntar "Como podemos interpretá-las?", "O que podemos deduzir delas?", ou ainda "Qual imagem de mundo elas podem nos oferecer?". Existem, no mínimo, algumas dezenas de interpretações da mecânica quântica, e apenas algumas propõem a existência de um observador universal, ou de uma "constante de observação universal", que podemos chamar, por analogia, de Deus. Como exemplos de tais abordagens, podemos citar as interpretações de James H. Jeans e Erwin Schrödinger. Ver SCHRÖDINGER, Erwin. Mi concepción del mundo. Barcelona: Tusquets, 1988; e ainda 
tratar de tal relação. Na próxima seção, veremos os modelos apresentados por Alexander, e na seção seguinte, analisaremos as concepções de relação entre ciência e fé de 24 participantes de uma pesquisa de opinião que responderam um questionário com questões sobre natureza da ciência e relação entre ciência e fé.

\section{Modelos teóricos de relação entre ciência e reliģião conforme Dennis Alekander}

Denis Alexander, biólogo molecular, em sua obra Modelos para relacionar Ciência e Religião, defende uma tese arrojada: religião e ciência são sistemas complexos e dinâmicos, que interagem, se aproximam ou afastam, de múltiplos modos. Nenhum modelo que busque explicar, isoladamente, a relação entre tais sistemas será plenamente bem-sucedido, pois por mais abrangente e verossímil que um modelo pareça ser, tende a não levar em conta todo dinamismo e complexidade das relações entre ciência e religião. Vários modelos diferentes podem contribuir para o entendimento de suas interações. Tal abordagem nos remete ao realismo polimodal, ou realismo dependente de modelo, apresentado por Stephen Hawking em O Grande Projeto. Conforme Hawking, nenhum modelo físico é capaz, se tomado de modo isolado, de oferecer-nos uma representação unificada da natureza. Somente a interação complexa entre diversos modelos sobrepostos poderia nos aproximar de tal conquista (HAWKING, 2011, p. 33). O que Hawking defende para os modelos físicos, aplicamos aqui aos modelos epistemológicos de relação entre ciência e religião. Alexander apresenta quatro modelos, que julga serem os principais: (1) conflito, (2) magistérios não interferentes, (3) fusão e (4) complementaridade. Vejamos cada qual:

\section{Conflito}

Este modelo seria defendido por pessoas que acreditam que entre religião e ciência há um conflito insuperável. Aqueles que defendem o modelo do conflito sustentam que ciência e religião são atividades opostas. Se algo pertence à ciência, então não pertence à religião; se pertence à religião, então não pertence à ciência.

Este modelo propone, como el nombre sugiere, que la ciencia y la religión están en oposición, y que esto ha sido siempre así. La idea la expresa claramente Worrall cuando escribe que "Ciencia y religión están en un conflicto irreconciliable. [...] No hay manera alguna en la que se pueda ser a la vez tanto científicamente correcto como un verdadero creyente religioso". Nótense tanto los elementos descriptivos como los normativos en tal afirmación (ALEXANDER. 2001, p. 1).

Conflito pressupõe não somente independência, separação ou indiferença, mas franca hostilidade. Podemos apontar como partidário de tal modelo o biólogo Richard Dawkins:

A religião fundamentalista está determinada a arruinar a educação científica de inúmeros milhares de mentes jovens, inocentes e bem-intencionadas. A religião não fundamentalista, 'sensata', pode não estar fazendo isso. Mas está tornando o mundo seguro para o fundamentalismo ao ensinar as crianças, desde muito cedo, que a fé inquestionável é uma virtude (DAWKINS, 2007, p. 294).

A cruzada de Richard Dawkins, logo se vê, não é apenas contra a religião fundamentalista, considerada por ele como fonte de ruína moral e grave impedimento à educação científica, como também contra a religião "sensata", porque, mesmo não propagando o ódio e a intolerância, como os fundamentalistas, esta inibiria, desde a juventude, o desenvolvimento do senso crítico, da atitude científica, gerando preconceitos nefastos

JEANS, J. H. O Universo Mysterioso. Tradução J. de Sampaio Ferraz. São Paulo: Companhia Editora Nacional, 1944. 
e afastando-nos da ciência e da razão. A origem do conflito pode ser - e muitas vezes de fato é - a atividade de grupos religiosos que não admitem que a ciência tenha algo a nos dizer acerca de questões fundamentais, baseando-se em uma fé na literalidade de suas escrituras sagradas.

Alexander critica o modelo do conflito sustentando que ele só pode existir quando a ciência e a religião adotam uma postura "expansionista", querendo extrapolar seus campos de atuação e oferecer respostas que vão além de seu escopo. Além disso, o modelo do conflito ignora a relação histórica entre ciência e fé religiosa como um dos principais motores da pesquisa científica:

Quizás el hecho que, más que ningún otro, desmantela el modelo del conflicto es la manera en que la fe religiosa ha contribuido a la emergencia histórica de la fe científica. Muchos de los filósofos naturales, que desempeñaron papeles claves en la fundación de nuestras disciplinas científicas actuales, fueron personas que vieron su fe en Dios como una motivación importante para explorar y comprender el mundo que Dios había traído a la existencia. (...) La idea de leyes científicas, articulada claramente por primera vez en los escritos de Newton, Boyle y Descartes, surgía de la idea bíblica de Dios como legislador. Actualmente, ningún historiador de la ciencia mantiene la visión de que el modelo del conflicto proporciona un marco satisfactorio en el que entender las interacciones históricas entre ciencia y religión. Cuando ha habido fricción, ha sido más parecida a las peleas ocasionales entre parientes cercanos, desde luego, no el tipo de enemistad que surge de una incompatibilidad intrínseca (ALEXANDER, 2001, p. 1).

O conflito, segundo Alexander, não pode nos oferecer uma imagem complexa da ciência. Ele ignora os casos históricos em que a fé religiosa motivou o trabalho de pesquisa de cientistas. Galileu é um bom exemplo. O filósofo natural escreveu a famosa carta à Cristina de Lorena, grã-duquesa de Toscana, em 1615. Sua intenção era defender que não havia contradição entre o texto bíblico e o sistema copernicano astronômico. Ambos eram compatíveis. Deus criou a Natura e a Scrittura. As duas são obras do Verbo divino, dois livros de um mesmo autor. Como compreender, então, o conflito entre aquilo que a Bíblia revela e o que a filosofia natural explica? Toda contradição é mera aparência, ocasionada pela erro do teólogo, que não interpretou corretamente a Scrittura, ou do filósofo natural, que falhou em investigar a Natura, o livro da natureza escrito em linguagem matemática.

Por que devemos interpretar a Bíblia? Por que a "Palavra de Deus" não é simplesmente clara e direta, sendo necessária uma exegese? [...] apenas pelo que diz respeito ao acomodar-se à capacidade de povos rudes e incultos, a Escritura não se absteve do obscurecimento de seus próprios dogmas, atribuindo até ao próprio Deus condições muitíssimos longínquas e contrárias à sua essência (GALILEU. 2009, p. 19).

A “Verdade Revelada” por Deus aos homens é sempre compatível com o nível de entendimento que a humanidade possui naquele momento histórico. A Scrittura se destina a salvar e guiar espiritualmente a humanidade e não a explicar a realidade física. Se, para salvar e orientar o ser humano, for necessário inspirá-lo por meio de um discurso simbólico, guia-lo por entre metáforas e alegorias, assim fará o Senhor. As Escrituras, quando falam da natureza, se adequam ao entendimento de cada época, povo e cultura. A tese dos dois livros (coexistência e compatibilidade entre Escritura e Natura) e o princípio de adequação (entre a Palavra de Deus e o nível de entendimento de um povo no momento histórico em que a Revelação é concedida) são ideias fundamentais da teologia secular de Galileu. Serão recursos retóricos para escapar da perseguição da Igreja? Pensamos que uma análise da obra de Galileu nos apresenta outro quadro: O grande pensador foi um teísta convicto, e sua fé inspirava seu desejo de conhecer a Natura.

Outro exemplo histórico interessante é o de Newton. A teologia natural é um elemento fundamental do Philosophice Naturalis Principia Mathematica. Sendo assim, o Principia, mesmo não sendo um tratado de teologia, é uma obra de física que assume a existência de Deus como condição fundamental para a compre- 
ensão do funcionamento do universo. Ao analisarmos trechos do Livro III, Parte I, da Óptica, de Newton, compreendemos a importância do conceito de Deus Supremo em seu pensamento. Na obra, Newton trata da natureza da luz e dos fenômenos óticos. O pensador concebe a natureza como um sistema ordenado, regido por leis universais. Desse modo, uma questão fundamental se impõe: qual a origem de "toda aquela ordem e beleza que vemos no mundo?". Será fruto do mero acaso? Newton defende que não seria racional concluir que o mundo se originou por acaso. Se analisarmos a natureza de modo crítico e meticuloso, concluiremos a existência de Deus como o Ser Supremo que imprimiu ordem ao mundo: um "Ser incorpóreo, vivente, inteligente, onipresente", que criou todas as coisas de modo harmônico, belo e ordenado (NEWTON, 2000, p. 279-280). Já citamos pensadores mais recentes, como Planck e Einstein, que consideraram a importância de alguma forma de religiosidade na pesquisa científica. Passemos ao modelo seguinte.

\section{Independência ou NOMA}

Uma abordagem menos ingênua e passional do que o modelo do conflito seria defender que ciência e religião são independentes ou não-interferentes ${ }^{2}$. Alexander destaca que Stephen Jay Gould defendeu a não interferência entre ciência e religião, que seriam campos de atividade muito diferentes.

El fallecido Stephen Jay Gould popularizó la noción de ciencia y de religión como pertenecientes a "Magisterios Que No Se Superponen" ("Non-Overlapping Magisteria" [NOMA] en el original inglés) en su Rock of Ages (traducido como: Ciencia versus Religion, un falso conflicto). Gould mantenía que la ciencia y la religión operan dentro de compartimentos separados, abordando diferentes tipos de preguntas, y, por tanto, no puede haber virtualmente conflicto entre ellas por definición. Además, Gould sostenía que la ciencia trata con hechos, mientras que la religión aborda cuestiones de ética, valor y propósito (ALEXANDER, 2001, p. 2-3).

Como seus objetos, práticas e pressupostos são distintos, não pode haver conflito entre ciência e religião. Alexander pensa que tal modelo também pode ser criticado, pois em sentido estrito não poderia explicar como alguns filósofos naturais e cientistas desenvolvem seu trabalho animados por uma fé religiosa, ou como cientistas não religiosos declaram enxergar na natureza elementos de harmonia, ordem e beleza, que os remete a algo sublime e sagrado, ainda que não identificado com quaisquer credos religiosos. Além disso, ciência e religião são atividades humanas, sociais, e, como tais, interagem historicamente em diversos âmbitos. O modelo também reforçaria uma separação problemática entre fatos, próprios da ciência, e valores, pertencentes à religião.

\section{Fusão}

De certo modo, os defensores do NOMA se contrapõem ao modelo do conflito quando consideram que ciência e religião são atividades não interferentes, mas os partidários do modelo de fusão negarão o conflito de modo enfático, propondo justamente o contrário.

Los modelos de fusión representan el polo opuesto del modelo NOMA en cuanto intentan difuminar completamente la frontera entre los tipos de conocimiento científico y religioso, o pretenden utilizar la ciencia para construir sistemas de pensamiento religioso, o viceversa. El plural "modelos" es necesario debido a que las diversas estrategias para conseguir la fusión son muy variadas (ALEXANDER, 2001, p. 3).

2 MNI: "Magistérios Não-Interferentes". 
Façamos uma distinção entre fusão forte e fusão fraca. Os modelos de fusão fortes sustentam que não existem distinções entre religião e ciência quanto ao conteúdo que informam, nem quanto ao objeto que analisam e aos valores em que se inspiram. O conhecimento científico pode comprovar as verdades reveladas pelas tradições religiosas, e as verdades reveladas podem guiar a pesquisa científica. Já modelos fracos, ou moderados, ressaltam que tais distinções podem ser sutis, e não muito claras, mas estão lá. Tais modelos podem ser propostos por cientistas e filósofos da ciência ou por religiosos. Quando cientistas e epistemólogos sustentam tal modelo, suas concepções podem ser, ao menos, de três naturezas:

a. a própria ciência é uma forma de experiência do sagrado, ou seja, de religiosidade ${ }^{3}$;

b. uma teoria científica pode comprovar a existência de Deus; e

c. a ciência pode confirmar a verdade revelada por uma tradição religiosa.

"Fusão" pode sugerir que ciência e religião são a mesma coisa. Seria um equívoco pensar dessa forma, ignorando todas as ricas peculiaridades de cada qual. Já a noção de interação preserva a autonomia de cada uma, embora destaque que ambas trocam influências e abrigam tensões. Por um rigor conceitual que busque refletir a complexidade das práticas de ciências, parece que a interação é um modelo mais desejável que a fusão, até porque um tipo de fusão pode ser um caso limite de interação forte.

Conforme Alexander (2001), o modelo de fusão pode ignorar que a ciência, para desenvolver-se, deve ser secular, ocorrer em instituições com espírito laico (mesmo se pertencentes a uma religião), e que assegurem que a pesquisa não será pautada por dogmas religiosos. Além disso, em contrapartida, a religião tem seus próprios ritos e valores, que não devem se subordinar aos avanços das ciências de uma época.

\section{Complementaridade}

Conforme Dennis Alexander (2001), o modelo de complementaridade defende que ciência e religião abordam a mesma realidade a partir de tratamentos diferentes, mas não antagônicos:

Este modelo sostiene que la ciencia y la religión se refieren a la misma realidad desde perspectivas diferentes, proporcionando explicaciones que no rivalizan entre sí, sino que más bien son complementarias. El lenguaje de la complementariedad fue introducido originalmente por el físico Niels Bohr al describir la relación entre las formas de partícula y onda de la materia; era necesario aferrarse a las dos formas de comprensión a la vez para hacer justicia a los datos. Desde el tiempo de Bohr, la idea de complementariedad se ha extendido enormemente dentro del campo ciencia-religión a fin de englobar cualquier entidad que necesite explicaciones en múltiples registros para definirla en toda su complejidad adecuadamente (ALEXANDER, 2001, p. 4).

De acordo com o modelo de complementaridade, ciência e religião comunicam informações acerca do mesmo sistema. O real é o objeto de ambas. Contudo, não comunicam as mesmas informações, nem abordam o sistema por meio dos mesmos métodos e nem pretendem alcançar resultados semelhantes. Um tratamento religioso revelará um aspecto da realidade diferente daquele revelado pela ciência tanto quanto a abordagem científica revelará um aspecto diferente daquele revelado pela religião. Ciência e religião são complementares, porque são partes do mesmo todo, embora não possam ser obtidas por um único "arranjo experimental" e nem expressas pelo mesmo sistema conceitual. Para Alexander (2001), este modelo tem a vantagem de levar em conta a complexidade da ciência e da religião enquanto empreendimentos históricos, sociais, que se relacionam de múltiplas formas com as culturas, e abarcam diversos objetos, alguns em comum.

3 Podemos pensar que tal item faz parte do modelo de interação, e não de fusão. Aqui, nós o situamos como um modelo de fusão com base no seguinte argumento: se por meio da ciência temos a experiência do sagrado, então, para nós, a experiência científica será de natureza religiosa. Desse modo, há distinção entre ciência e religião institucionalizada, mas não entre experiência científica e experiência religiosa. 
No entanto, tal modelo também pode sugerir uma divisão artificial entre fatos e valores, como se a ciência lidasse sempre com fatos e nunca com valores, e a religião lidasse sempre com valores e nunca com fatos.

Ao dizer que ciência e religião abordam o real a partir de tratamentos, ou "arranjos experimentais" distintos, podemos endossar uma compreensão de que a ciência seria "factual" ao passo que a religião seria valorativa. Tal divisão nos parece esquemática e sem aporte empírico na medida em que ignora que os praticantes de ciências podem ser influenciados por seus valores (inclusive os religiosos) na construção dos próprios fatos científicos.

Alexander (2001) reconhece os inúmeros conflitos entre atores científicos e religiosos, mas pensa que tais sejam pontuais, e não elementos necessários e estruturais de ambas as atividades. Da mesma forma, aponta igualmente os limites dos outros modelos, apesar de seus avanços. É prudente considerar que as relações entre ciência e religião não podem ser plenamente expressas por nenhum modelo particular. O que estamos defendendo aqui é que todos os modelos são incompletos quando tomados isoladamente. O conflito ignora os casos de influência positiva mútua, a fusão tende a subestimar as tensões, incongruências e "possíveis" ataques históricos recíprocos, ainda que pontuais. O modelo de não interferência não pressupõe hostilidade, mas baseia-se em uma independência total, dificilmente sustentável quando analisamos casos em que os sentimentos religiosos e científicos estão imbricados, e os cientistas relatam a experiência de uma religiosidade no trabalho de pesquisa. Por último, a complementaridade, como vimos, pode nos sugerir que a ciência é despida de valores e se atém aos fatos, ao passo que a religião só trata de valores e encontra-se apartada do mundo dos fatos. Tal visão dicotômica ignora a complexidade tanto da ciência quanto da religião. Quando deixamos de considerar que um modelo em particular é uma representação satisfatória do real, por que não leva em conta modos de interação entre ciência e religião previstos por outros modelos, podemos buscar uma abordagem mais complexa e plural e menos dicotômica.

Pensamos que para a compreensão das relações entre ciência e religião uma superposição de todos os modelos pode ser uma abordagem mais fecunda do que a adesão a um modelo em particular. Tal perspectiva pluralista, poderíamos chamá-la de "hipótese polimodal em estudos de ciência e religião", preservaria certas proposições de cada modelo, combinando-as para formar uma imagem mais complexa. Conforme tal hipótese "As interações entre ciência $(\mathrm{C})$ e religião $(\mathrm{R})$ ocorrem de modo tão complexo e em tantas dimensões (metafísica, epistemológica, social, cultural, institucional, psicológica etc.) que somente um modelo flexível e plural, capaz de conter os casos em que C e R são (a) conflitantes, (b) reciprocamente influentes, (c) independentes e (d) complementares, pode nos oferecer uma representação verossímil, isto é, mais próxima da realidade histórica".

\section{Concepções de relação entre ciência e religião de pós-graduandos do Instituto de Biofísica da UFRJ}

Em dezembro de 2017, o Instituto de Biofísica Carlos Chagas Filho, do Centro de Ciências da Saúde da Universidade Federal do Rio de Janeiro promoveu o "II Encontro de Ciência e Cultura do IBCCF $^{\circ}$ da UFRJ: uma discussão sobre ciência e fé". Nesse contexto de trabalhos explorando as relações entre ciência, fé e religião, consideramos oportuno aplicar aos participantes, estudantes de mestrado e doutorado do Instituto, um questionário com o intuito de verificar como concebiam a ciência, seu valor, e sua relação com a fé religiosa.

O questionário não seguiu nenhum padrão convencional de aferição da concepção de natureza da ciência $(\mathrm{NdC})$ do público alvo, tais como o VNOS-C ${ }^{4}$. Pela peculiaridade de nossa intenção e pela especificidade do evento e do público alvo, decidimos compor nosso próprio questionário, conciso e pontual. Os questionários foram aplicados a 24 pesquisadores pós-graduandos.

O questionário contemplou as seguintes questões.

4 Para conhecer o VNOS-C no original consultar: <https://science.iit.edu/sites/science/files/elements/mse/pdfs/VNOS(C). pdf > Ultimo acesso em 17/07/2017 
1. Qual é o valor da ciência?

2. Como ciência e religião se relacionam?

3. Os valores estão presentes na pesquisa científica?

4. A crença religiosa influencia em seu trabalho como cientista?

Vejamos, caso a caso, como foram as respostas. A primeira questão visou mensurar como os participantes compreendiam a natureza e a importância da ciência. Tivemos uma divisão simétrica de opiniões. Dos entrevistados, $42 \%$ responderam que o valor da ciência é "inestimável", "sublime", "intrínseco", que a ciência é a "busca da verdade", da "compreensão da verdade", que "busca o conhecimento" a "compreensão do mundo", um fim em si mesmo. Podemos chamar tal visão de "concepção epistêmica da ciência". Exatamente outros $42 \%$ responderam que o valor da ciência é produzir tecnologia e inovação, possibilitar o desenvolvimento econômico e o bem-estar social. Digamos que se trata de uma concepção "instrumental" ou "utilitarista" de ciência, conforme a qual ela é um meio para, e não um fim ${ }^{5}$. Respostas alternativas, que não podem ser classificadas como pertencentes a tais concepções predominantes, foram oferecidas por $16 \%$.

Podemos destacar duas respostas que expressam bem as duas concepções de ciência. No caso da concepção epistêmica, um participante respondeu a questão do valor da ciência dizendo que:

A ciência é de valor inestimável para os seres humanos. É a forma de compreendermos a nossa própria natureza e tudo o que nos cerca e nos afeta, e que nos permite atuar em busca do desenvolvimento (Participante $n^{\circ} 4$ ).

Uma resposta que evidencia bem a concepção utilitarista do valor da ciência é

O conhecimento científico através de suas descobertas leva a um desenvolvimento social e econômico e com isso ocorre uma melhora na qualidade de vida de toda a humanidade (Participante $\mathrm{n}^{\circ}$ 21).

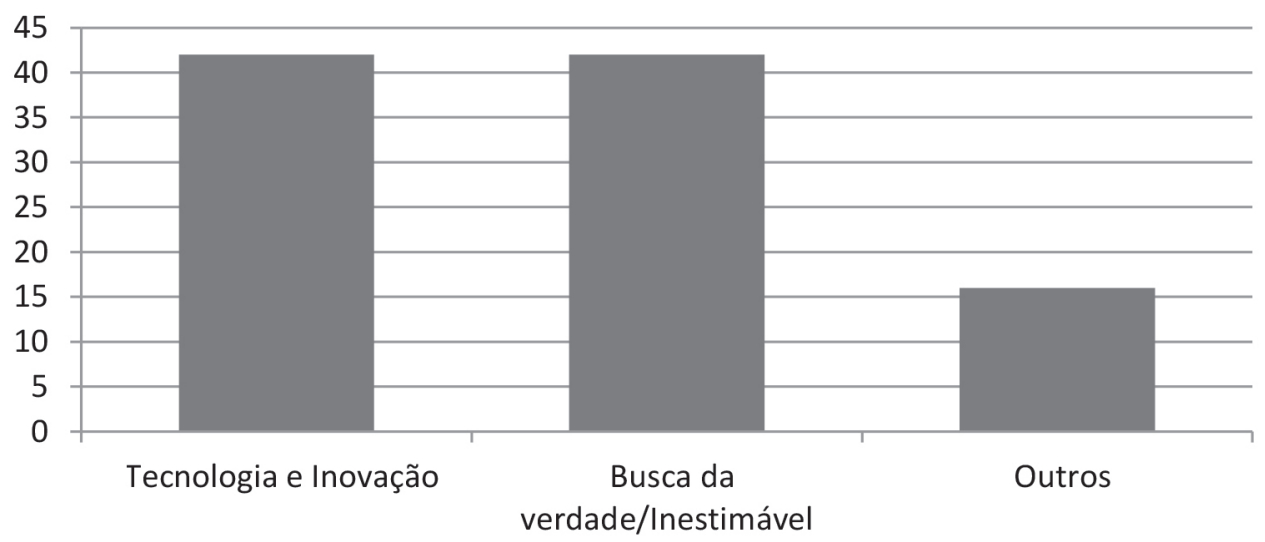

Gráfico 1: Distribuição percentual das respostas à questão “Qual é o valor da ciência?”.

Haverá uma dicotomia real entre o valor epistêmico e cultural da ciência e seu potencial de produzir tecnologia e inovação, gerando desenvolvimento econômico e bem-estar social? Será que dividir as concepções de ciência entre "busca da verdade", cujo valor é inestimável, por um lado, e "produção da utilidade", de valor

5 Não comunicamos nenhuma teoria da verdade ou do conhecimento aos participantes, tampouco pedimos que explicassem o que entendem por "verdade", "conhecimento", "compreensão". Também não questionamos o que consideram por "sublime" e "inestimável". Da mesma forma não verificamos o que entendiam por "utilidade", "progresso", "desenvolvimento". As respostas foram dadas de modo espontâneo, sendo agrupadas em duas grandes categorias. O objetivo da pesquisa não era verificar o entendimento dos entrevistados, mas como responderiam livremente a determinadas questões. 
prático, por outro, não gera um falso problema? Se os praticantes de ciências pensam que não há contradição entre "buscar a verdade" ou a natureza "sublime" e "inestimável" da ciência e "servir ao progresso" ou sua natureza "utilitária", então não há dicotomia para eles. Do contrário, estariam reforçando a dicotomia? O fato de um participante mencionar a "busca da verdade" e dar menos ênfase ao desenvolvimento tecnológico, por exemplo, não significaria que ele nega a dicotomia? Se ele menciona apenas um aspecto e omite o outro, ainda assim, pode ser que sua visão não seja dicotômica.

No gráfico 1 chegamos aos $42 \%$ x $42 \%$ classificando as respostas conforme o seguinte critério: "Pela resposta completa, a concepção deste praticante é $x$ ou $y$ ?". Ao fazermos isso, a dicotomia tornou-se um pressuposto, um dado de entrada. Mas o que acontece se eliminamos a dicotomia e adotamos outro critério? O que acontece se, a despeito do tom geral da resposta, independente da ênfase da resposta, agrupamos em categorias diferentes as respostas que combinaram "verdade" e "utilidade", daquelas que enfatizaram uma ou outra?

Revisamos todas as respostas a partir desse novo critério: agruparíamos as respostas que combinassem a concepção de que a motivação da ciência é a busca pela verdade, com aquela de que ela gera tecnologia e inovação. No outro grupo juntaríamos todas as respostas que mencionaram apenas um aspecto, negando ou omitindo o outro. O resultado foi bastante diferente daquele obtido inicialmente.

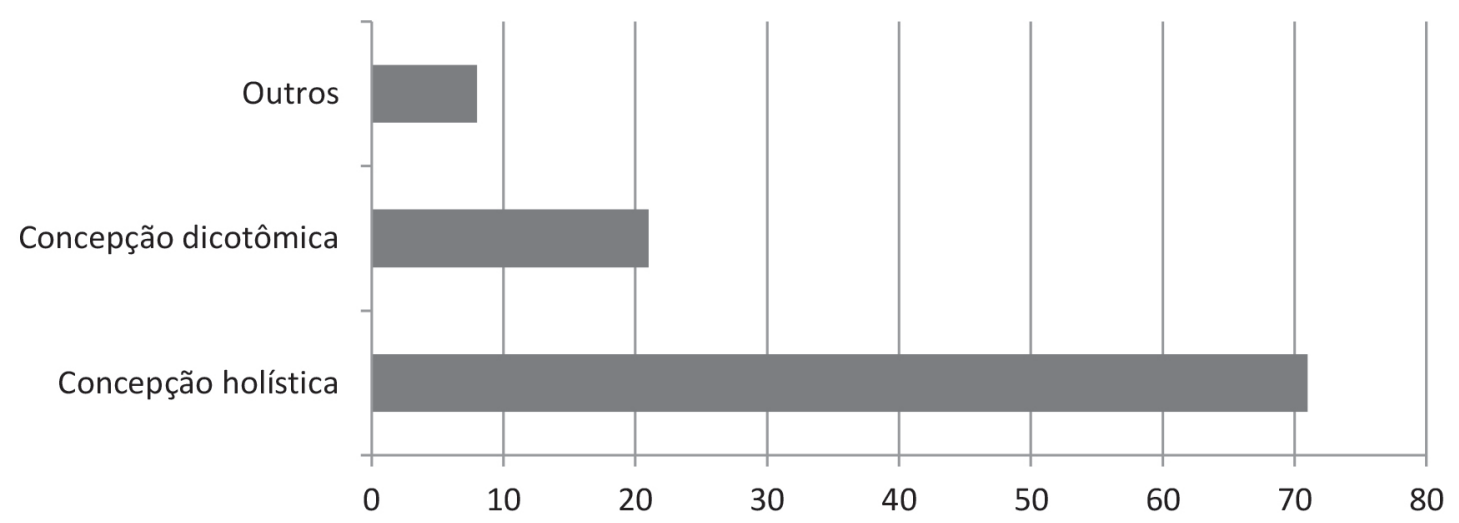

Gráfico 1.1: Distribuição percentual das respostas à questão “Qual é o valor da ciência?”.

As respostas de modo "holístico" foram de 71\%, acomodando "verdade" e "utilidade" em uma só resposta, ainda que enfatizassem mais uma dimensão do que outra. Os que reforçaram uma posição potencialmente dicotômica somaram $21 \%$, afirmando que o valor da ciência era $x$ e omitindo $y$, e vice-versa. Dentre as concepções potencialmente dicotômicas, os que privilegiaram apenas a dimensão utilitária da ciência foram $80 \%$, e 20\% lembraram apenas da dimensão epistêmica. Concluímos assim que, conforme esse novo parâmetro, a maioria (71\%) dos participantes pensa que as concepções epistêmica e utilitária não são perspectivas contraditórias. Outros $21 \%$ não afirmam a contradição, mas suas respostas favorecem apenas uma perspectiva. Por isso chamamos tal posição de potencialmente dicotômica.

Tendo em vista os quatro modelos de relação entre ciência e religião, a próxima questão buscava verificar o entendimento dos entrevistados acerca dos mesmos. Ciência e religião se relacionam de qual modo?

- São antagônicas, de um conflito insuperável?

- São independentes, nem se reforçam, nem se anulam, podendo conviver em paralelo?

- São complementares, tratando de modos distintos dos mesmos objetos?

- Interagem de modo complexo, com convergências e divergências, podendo se beneficiar mutuamente? 
Apenas $8 \%$ responderam que ciência e religião são atividades antagônicas, confirmando que o modelo do conflito não reflete o entendimento majoritário dos praticantes de ciências entrevistados. Outros 33\% responderam que ciência e religião são independentes e também $33 \%$ que são complementares, enquanto $22 \%$ responderam que ciência e religião interagem de modo complexo. Se somarmos as respostas favoráveis ao modelo de interação forte e ao modelo complementar, temos que para $55 \%$ dos entrevistados a relação entre ciência e religião não é nem indiferente e nem negativa.

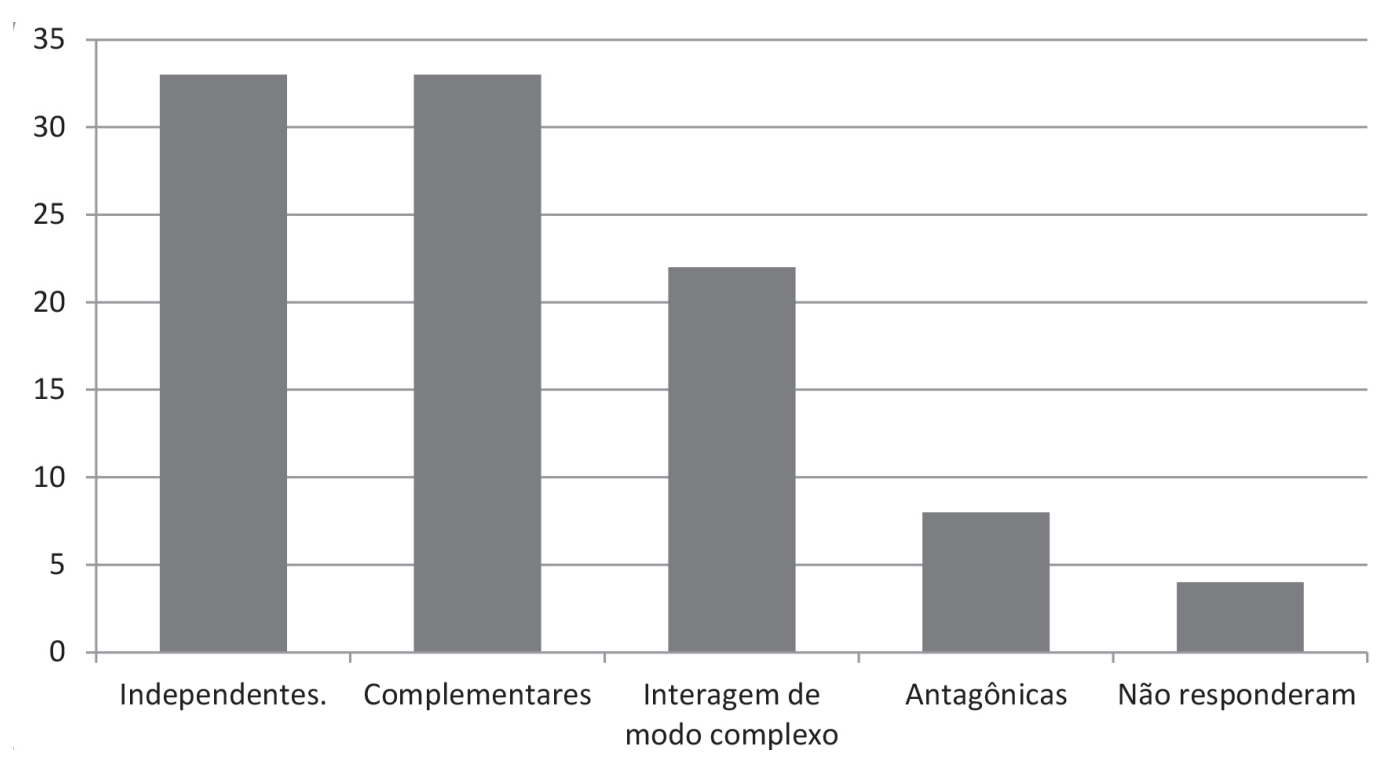

Gráfico 2: Distribuição percentual das respostas à questão da relação entre ciência e religião.

Tal resultado poderia parecer realmente surpreendente, pois é bastante contrário à percepção de senso comum, do leigo, que, conforme Roland Numbers em Mitos e verdades em ciência e religião: uma perspectiva histórica adere ao modelo de conflito, acreditando haver entre ciência e religião uma incompatibilidade insuperável (NUMBERS, 2011, p. 198). No entanto, o modelo do conflito pode ser bem mais popular entre europeus e norte-americanos. Será mesmo senso comum entre brasileiros? O povo brasileiro parece ser bem mais flexível e plural (NEGRÃO, 2008). Talvez, por conta de tal pluralismo, não tenha propensão a afirmar uma contradição entre ciência e religião.

Não foi verificada uma correlação forte entre as duas respostas. Pareceria coerente supor que os que defenderam a concepção epistêmica de ciência fossem também favoráveis a negar o conflito ou a independência entre ciência e religião. A coincidência está no fato de que $42 \%$ disserem que o valor da ciência é "inestimável" e "sublime", e 55\% negaram o conflito e a independência - números próximos. Enquanto isso, $42 \%$ assumiram uma concepção utilitarista de ciência, ao passo que $41 \%$ responderam que são antagônicas ou independentes. No entanto, não podemos afirmar tal correlação entre as respostas, o que significa que o entendimento dos entrevistados é mais complexo, menos polarizado e esquemático, menos evidente, do que poderíamos supor. A resposta de um participante é emblemática. Quando questionado sobre o valor da ciência afirmou que:

O valor da ciência para mim é inestimável. Acredito que Deus inspira os homens para que tenhamos tanto progresso científico. Sem a ciência, não desvendaríamos tantos mistérios e não conheceríamos a vida como ela é hoje (Participante n ${ }^{\circ}$ 9).

Poderíamos concluir apressadamente que tal participante respondera que a relação entre ciência e religião é de interação forte, com benefícios mútuos, ou ao menos de tipo complementar, mas, no entan- 
to, o participante disse que ciência e religião são independentes. Haverá uma contradição nas respostas? Independência não implica hostilidade, mas reconhecer uma diferença ontológica entre ciência e religião, que não se contradizem, nem se reforçam. Se o participante pensa que Deus inspira os cientistas, não seria coerente responder que ciência e religião interagem de modo forte e complexo? Ele também poderia adotar a complementaridade, acreditando que embora ciência e religião sejam modos diferentes de abordar a realidade, a crença religiosa pode influenciar o cientista no nível pessoal. Enfim, não existem respostas certas ou erradas, e tais questionários nos revelam a complexidade, as tensões e contradições, presentes entre os praticantes de ciências.

No Gráfico 3, podemos observar um dado bastante relevante: $92 \%$ dos participantes pensam que a pesquisa científica não é neutra em relação a valores. Valores culturais, religiosos, morais e sociais estariam presentes, de algum modo, nas práticas científicas.

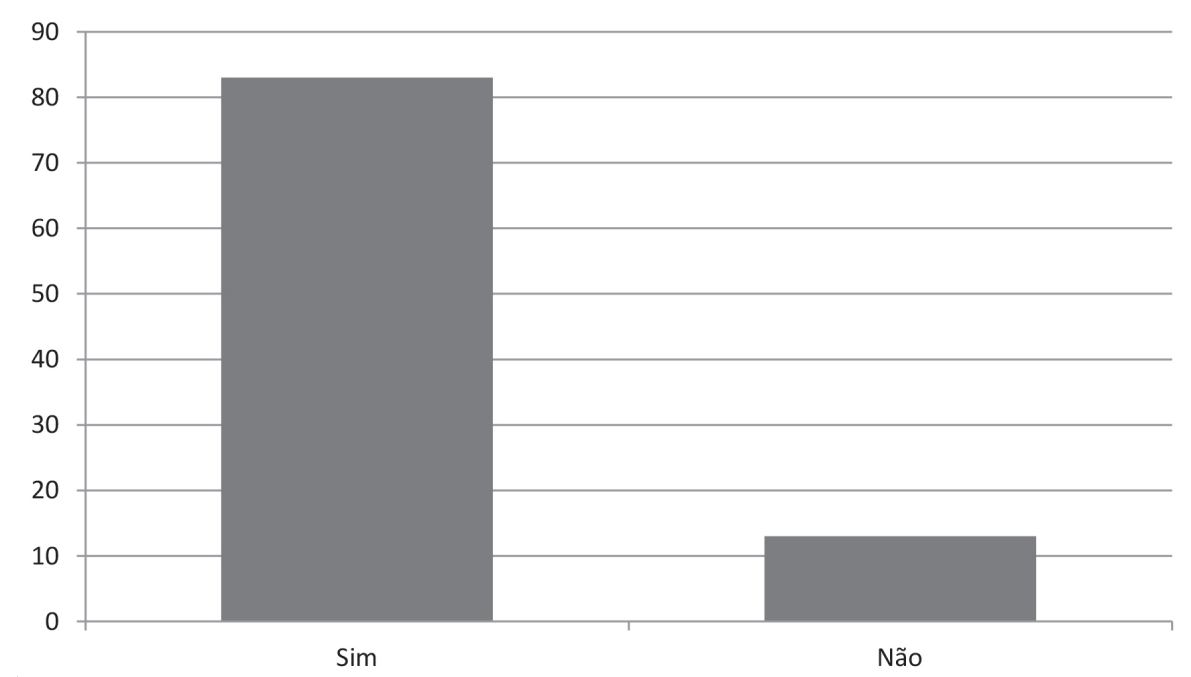

Gráfico 3: Distribuição percentual das respostas à questão da presença dos valores na ciência.

Vale ressaltar uma dessas respostas para ilustrar tal entendimento. A resposta selecionada demonstra como o entendimento do participante naturaliza a presença dos valores religiosos:

Toda noção moral e valores que se conhece, adveio da religião. Mesmo que o indivíduo nunca tenha sido religioso por um dia sequer, o conceito veio de lá. Inevitavelmente valores morais, culturais e éticos irão nortear os destinos de alguns tipos de pesquisa, sejam advindos de seus próprios autores como das pessoas ou instituições que as financiam (Participante $\left.\mathrm{n}^{\circ} 16\right)$.

Por último, perguntamos se a crença religiosa os influenciava em suas pesquisas. Dos participantes, $62 \%$ responderam que não, mas $38 \%$, número expressivo, admitiu que sim. Dentre as respostas negativas uma nos chamou a atenção:

Não, pois acredito que explicações sobrenaturais não se aplicam no conhecimento adquirido pelo método científico (Participante $\mathrm{n}^{\circ} 7$ ).

É interessante notar que o participante identifica as crenças religiosas apenas ao sobrenaturalismo de algumas tradições, não levando em conta que tais crenças podem ser de natureza moral, por exemplo. Duas respostas afirmativas também merecem destaque. A primeira, pela sofisticação da análise sociológica e psicológica subjacente à resposta: 
Acredito que dificilmente uma pessoa com determinada crença consegue desvencilhar-se completamente desta no ambiente de trabalho ou em outro ambiente qualquer (Participante $\left.\mathrm{n}^{\circ} 13\right)$.

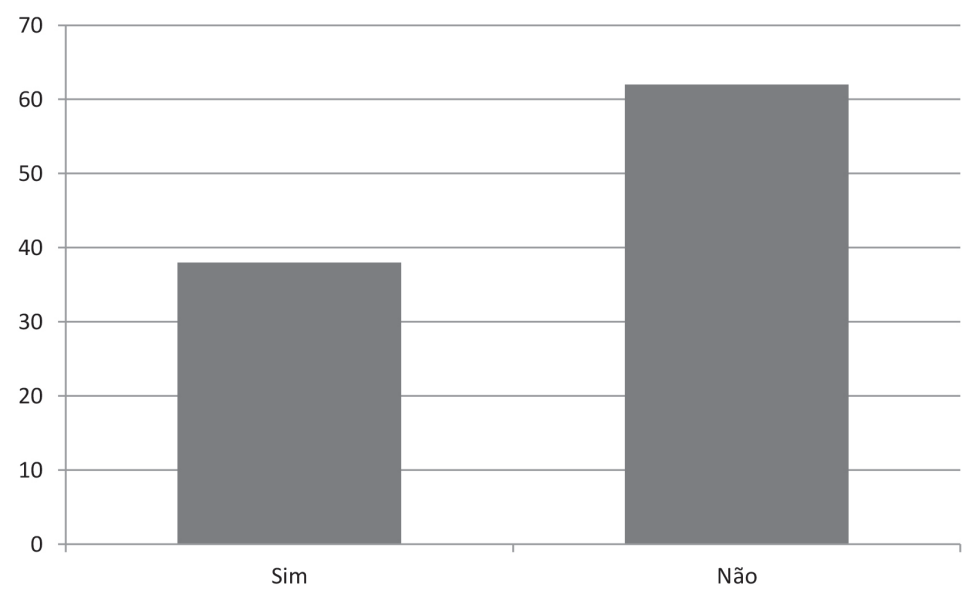

Gráfico 4: Distribuição percentual das respostas à questão da influência da crença religiosa.

A segunda resposta afirmativa que nos chamou a atenção, o fez por conta de seu aspecto único e incomum, ao menos em se tratando da amostragem desta pesquisa. Conforme a participante, suas crenças religiosas influenciam seu trabalho de pesquisa:

Sim, eu acredito que as divindades existentes em minha religião podem me auxiliar durante os experimentos trazendo energias boas e me ajudando a não cometer falhas que comprometam o processo (Participante $\mathrm{n}^{\circ} 24$ ).

\section{Considerações finais}

Acreditamos que no imaginário do senso comum ciência e fé são atividades conflitantes e mesmo excludentes. No entanto, vimos que na literatura especializada sobre ciência e religião, o conflito é apenas um dos modelos de relacionamento entre estas duas atividades. Além disso, pensamos que o conflito pode ser um modelo popular entre europeus e norte-americanos, mas não entre os brasileiros. O Brasil é um país muito plural, multiétnico, cheio de sincretismos religiosos, com uma população mais aberta ao diálogo entre ciência e religião. Ao coletarmos as concepções de ciência e de relação entre ciência e fé de um público composto por 24 pesquisadores, pós-graduandos de doutorado e mestrado do IBCCFO-UFRJ, podemos constatar que, de fato, nenhum dos modelos elaborados por Alexander, a saber, conflito, não interferência, fusão e complementaridade, foi capaz de explicar, isoladamente, como os praticantes de ciências concebem a relação entre a pesquisa científica e a fé religiosa. Os resultados obtidos demonstram que o pluralismo teórico é a regra, havendo verdadeira diversidade nas opiniões expressas. Isto salienta que as práticas científicas são fenômenos culturais e sociais complexos, que em meio a tensões, divergências e convergências, podem se combinar com os mais diversos sistemas de crenças, o que parece confirmar nossa hipótese polimodal em estudos de ciência e religião. A pesquisa revelou também que para a maioria dos entrevistados não há dicotomia entre a busca da verdade, a natureza "sublime" e "inestimável" da ciência, e o desenvolvimento de tecnologia e inovação. Os resultados obtidos demonstraram também que, para os participantes da pesquisa, a ciência não é neutra, possuindo valores morais, sociais e culturais que se relacionam de modo complexo com as crenças oriundas das tradições religiosas. 


\section{Arradecimentos}

Agradeço à Prof ${ }^{a}$. Dra ${ }^{a}$. Maria Cristina Machado Motta do Instituto de Biofísica da UFRJ, sem a qual não teríamos realizado essa pesquisa. Ela promoveu o encontro, nos convidou para apresentar trabalho sobre Ciência e Fé, e participou ativamente da aplicação da pesquisa. Ao Prof. Dr. Antônio Augusto Passos Videira da UERJ por suas orientações na elaboração do questionário. Na construção do questionário foram muito importantes as orientações da Prof ${ }^{\text {a }}$. Dra. Cristina Buarque de Holanda do Instituto de Estudos Sociais e Políticos da UERJ. Agradeço também, pelos diálogos inspiradores, ao meu supervisor de pós-doutoramento, o Prof. Dr. André de Oliveira Mendonça do Instituto de Medicina Social da UERJ e a todos os colegas de grupo de pesquisa "Estudos Sociais e Conceituais de Ciência, Tecnologia e Sociedade". Agradeço ao meu irmão, Adilson Carvalho da Silva Filho, por longos anos de um debate interminável sobre as interações entre ciência e fé.

\section{Referências}

ABDALLA, Elcio. Teoria quântica da gravitação: Cordas e Teoria-M. Revista Brasileira de Ensino de Física, v. 27, n. 1, p. 147-155, 2005.

ALEXANDER, Denis. Modelos para relacionar Ciência e Religião. Tradução Guilherme V.R. de Carvalho. Faraday Papers. Cambridge: Faraday Institute for Science and Religion, 2007. Disponível em:<http//www.faraday.st-edmunds. cam.ac.uk>. Acesso em: 20 jun. 2014.

Modelos para relacionar ciencia y religión. Faraday Papers.Cambridge: Faraday Institute for Science and Religion, 2011. Disponivel em:<https://www.faraday.st-edmunds.cam.ac.uk/resources/Faraday\%20Papers/Faraday\%20 Paper\%203\%20Alexander_SPAN.pdf>. Acesso em: 20 jun. 2014.

BARBOUR, I. G. Quando a ciência encontra a religião. Inimigas, estranhas ou parceiras?São Paulo: Cultrix, 2004.

BOHR, Niels. Física atômica e conhecimento humano: ensaios 1932-1957. Tradução Vera Ribeiro. Rio de Janeiro: Contraponto, 1995.

BÖTTIGHEIMER, Christoph. Manual de Teologia Fundamental: A racionalidade da questão de Deus e da revelação. Tradução Markus A. Hediger. Petrópolis: Vozes, 2014.

DARWIN, Charles. A Origem das Espécies. Tradução André Campos Mesquita. São Paulo: Escala, 2009.

DAWKINS, Richard. Deus, um delírio. Tradução Fernanda Ravagnani. São Paulo: Companhia das Letras, 2007.

EINSTEIN, Albert. Como eu vejo o mundo. Tradução H. P. de Andrade. Rio de Janeiro: Nova Fronteira, 1981.

FEYNMAN, Richard. Física em 12 lições. Tradução Ivo Korytowski. Rio de Janeiro: Ediouro, 2005.

FREIRE JR, O., PESSOA JR, O., and BROMBERG, JL., orgs. Teoria Quântica: estudos históricos e implicações culturais [online]. Campina Grande: EDUEPB; São Paulo: Livraria da Física, 2011. 456 p. ISBN 978-85-7879-060-8. Available from SciELO Books .

GALILEI, Galileu. Ciência e Fé: cartas de Galileu sobre o acordo do sistema copernicano com a Bíblia. São Paulo: Ed. da UNESP, 2009.

GALISON, Peter. Culturas Etéreas e Culturas Materiais. In: GIL, Fernando (Org.).A Ciência tal qual se faz. Lisboa: Edições José Sá da Costa, 1999. p. 395-414.

GLEISER, Marcelo. A Dança do Universo: Dos mitos de criação ao Big-Bang. São Paulo: Companhia das Letras, 1997.

HAWKING, Stephen; MLODINOW, Leonard. O Grande Projeto: Novas respostas para as questões definitivas da vida. Tradução Mônica César Santos Friaça. Rio de Janeiro: Nova Fronteira, 2011.

HARRISON, Peter (Org). The Cambridge Companion to Science and Religion. Cambridge: Cambridge University Press, 2010.

HEISENBERG, Werner. Física e filosofia. Brasília: Editora da Universidade de Brasília, 1987.

JAMMER, Max. Einstein e Religião: Física e Teologia. Rio de Janeiro: Contraponto, 2000.

JEANS, J. H. O Universo Mysterioso. Tradução J. de Sampaio Ferraz. São Paulo: Companhia Editora Nacional, 1944. 
KOYRÉ, Alexandre. Do espaço fechado ao universo infinito. Rio de Janeiro: Forense Universitária, 2006.

LACEY, Hugh. Existe uma distinção relevante entre valores cognitivos e sociais?ScientiaStudia, São Paulo, v.1, n. 2, p. 146, 2003.

. Aspectos cognitivos e sociais das práticas científicas. ScientiaStudia, São Paulo, v.6, n. 1, 2008.

MARICONDA, Pablo Rubens. O controle da natureza e as origens da dicotomia entre fato e valor. Scientioe Studia, São Paulo, v. 4, n. 3, p. 453-72, 2006.

NEGRAO, Lísias Nogueira. Pluralismo e multiplicidades religiosas no Brasil contemporâneo. Soc. estado., Brasília , v. 23, n. 2, p. 261-279, 2008 .

NEWTON, Isaac. Principia: Princípios Matemáticos da Filosofia Natural. Tradução Trieste

Ricci. São Paulo: Nova Stella / EDUSP, 1990.

Os Pensadores. São Paulo: Nova Cultural, 2000.

NUMBERS, Ronald. "Mitos e verdades em ciência e religião: uma perspectiva histórica” in PASSOS, João Décio; SOARES, Afonso Maria Ligorio (Org.). Teologia e Ciência: Diálogos acadêmicos em busca do saber. São Paulo: Educ/ Paulinas, 2008.

PASSOS, João Décio; SOARES, Afonso Maria Ligorio (Org.). Teologia e Ciência: Diálogos acadêmicos em busca do saber. São Paulo: Educ/Paulinas, 2008.

PLANCK, Max. Autobiografia científica e outros ensaios. Tradução Estela dos Santos Abreu. Rio de Janeiro: Contraponto, 2012.

POLKINGHORNE, John. Teoria quântica. Tradução Iuri Abreu. Porto Alegre: L\&PM, 2012.

RUSSEL, Bertrand. História da Filosofia Ocidental. Tradução Breno Silveira. São Paulo: Companhia Editora Nacional, 1969.

SCHRÖDINGER, E. Mi concepción del mundo. Barcelona: Tusquets, 1988. . A Natureza e os Gregos: seguido de Ciência e humanismo. Lisboa: Edições 70, 1996.

WEIZSÄCKER, Carl von. La importância de la ciencia. Tradução Juan Carlos García Borrón. Barcelona: Labor, 1972. 